\title{
ANALYSIS OF LONG-TERM MEASURED EXTERIOR AIR TEMPERATURE IN ZILINA
}

\author{
Daniela JURASOVA ${ }^{1, *}$ \\ ${ }^{1}$ Department of Building Engineering and Urban Planning, Faculty of Civil Engineering, University of \\ Žilina, Univerzitná 8215/1, 01026 Žilina, Slovakia. \\ corresponding author: daniela.jurasova@fstav.uniza.sk.
}

\section{Abstract}

The climate change assumes nowadays on significance. Weather data may be available on various time scales - long-term, minutes, hours, days, periods, years. Measurements of air temperature are realized for a long time. Data in Slovakia are available from few weather stations of Slovak Hydrometeorological Institute (SHMI). For long-term and wide-ranging measurement of various parameters this can be complicated and expensive. This paper is focused on temperature measurement near the experimental laboratory. Estimation of daily, monthly and yearly mean temperatures is done in different ways. Results from experimental temperature measurement, in a way of selection of unusual extremes are presented. Shorter recording intervals describe the temperature courses in a more pertinent way.
\end{abstract}

Keywords:

Exterior air;

Temperature measurement; Minimum and maximum temperature.

\section{Introduction}

The reference file is a data file of suitable meteorological elements, which represents a longterm climate. The specified year or the multi-year period, over which all parameters are calculated, shall be quoted with the values of the parameters [1]. Weather is an influencing parameter for building simulations, which strongly forms the results. Accurate weather data are crucial for building performance evaluation [2]. Experimental weather station now records measured values in a time step of 1 minute and some time ago it was a 10-minute recording interval [3]. This enables to use precisely obtained data for exterior boundary conditions as input data for building simulations. It is vital to understand the temperature characteristics outside buildings [4]. Summer overheating of buildings is actually of great interest. Effective energy use and saving is also highlighted and it is closely connected to simulation models created as precise as possible. Temperature is an important part of external climate models, used for computer building simulations. Well known interaction "building external climate - energy" recently leads to numerous analyses $[2,5,6]$. Designing sustainable buildings is a challenge for our times. Especially researchers are faced in particular with climate change [7]. Computer simulation with use of precisely given boundary conditions helps to predict behavior of the building. Crucial for this is the exterior of the building, represented by weather file in suitable form. Accurate modelling of long term performance of building should be ideal under mean conditions, but the extremes could considerably influence behavior of the structure. The accurate future data are not available. Past data must be processed for statistical analysis of the conditions [8]. Climate change becomes more and more visible. At least a 10-year measuring period should be used for determination of a reference file (this is recommended by meteorologists). Ideal for evaluation is as long period as possible. Monthly temperature should be compared to the reference file of the weather station, followed by the evaluation if temperature was under or above the reference value. After collecting the data file consisting of a 5-year measurement period, the deeper analysis of measured parameters is planned. The positive weather year should be understood as the opposite to the critical weather year and it has an impact on reliability on numerical simulations [9]. Building simulations become more and more sophisticated. One of the key parts of an accurate simulation of hygrothermal performance is the determination of boundary conditions, especially of the exterior ones. 


\section{Measurement}

Measurement of exterior air temperature is continuously recorded since May 2014 by experimental weather station and it still runs. The device used for the measurement is Ahlborn Meteo FMA520. This weather station measures following meteorological variables: air temperature, relative humidity, atmospheric pressure, rainfall, global solar radiation, wind velocity and direction. It could be characterized as dry-bulb air temperature. The device is calibrated regularly according to the defined plan finished with obtained certificate. Firstly it came to the test measurement inside the laboratory to verify the measuring device. Sources of data come from own observations from an experimental mobile weather station.

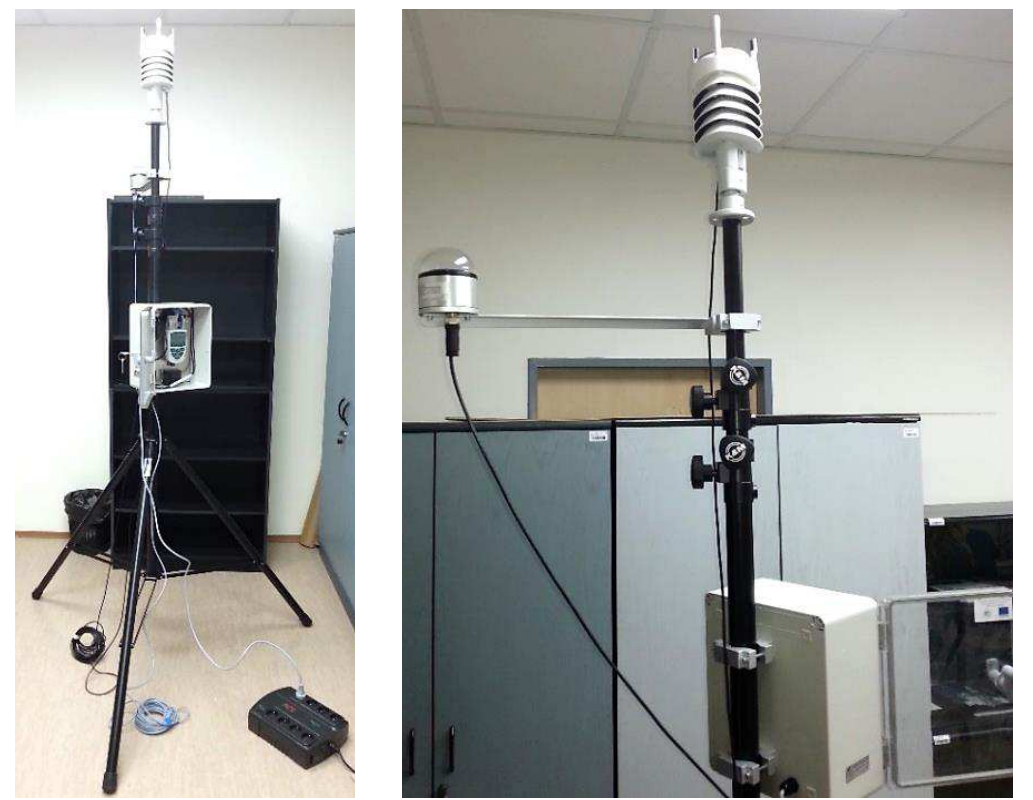

Fig. 1: Test measurement before installation into the exterior (Ahlborn Meteo FMA520).

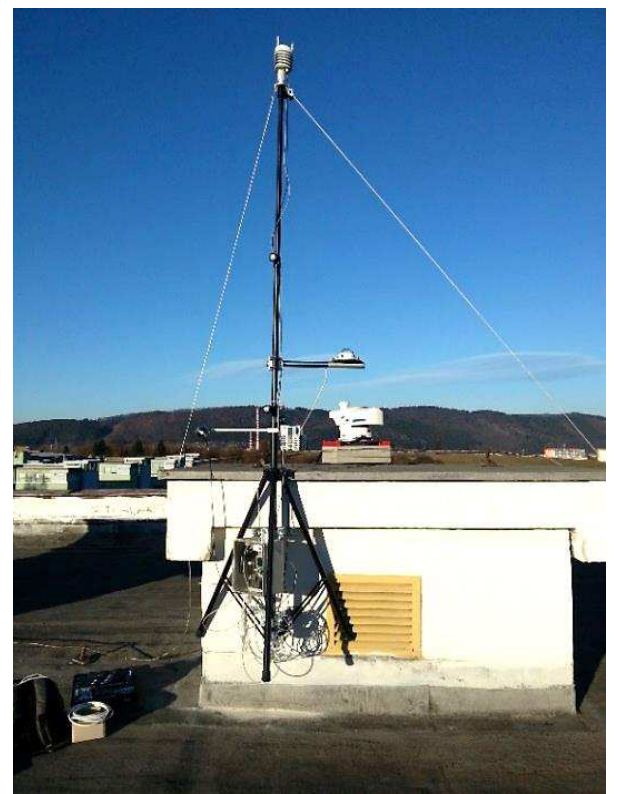

Fig. 2: Location for the exterior measurement.

The method for estimation of daily and monthly mean temperatures is a process dependent on the accessible database. It varies from country to country, depending on factors like the frequency of available observations, the time of observations and, more recently, the availability of automatic stations [10]. Exterior air temperature measurement which is at our disposal has a variable recording time interval. Temperatures are recorded in a 1-minute time step. Such a detailed measurement offers more possibilities of evaluation and a great accuracy. 


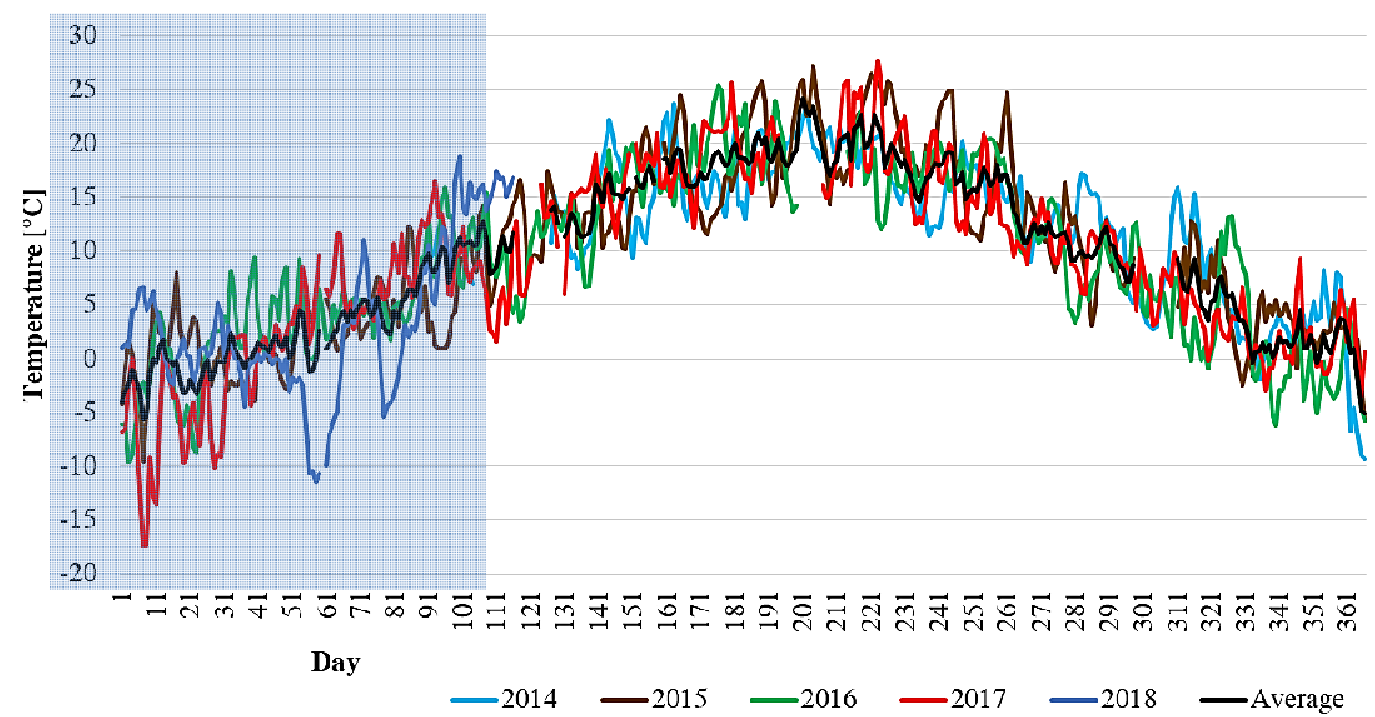

Fig. 3: Recordings of a long-term temperature measurement (highlighted part is shown in Fig. 4 and Fig. 5 in detail).

As Fig. 3 shows, there are some periods which indicate extremes in relation to average values from the whole measuring period (e. g. January 2017 and 2018, February 2016, March 2018, area marked in blue shading). The period January - April was described below (Fig. 4, Fig. 5). Fig. 3 should give an illustration about variability of individual months from various years from the point of view of measured temperature, which is one of the crucial factors influencing summer overheating or heat loss in winter.

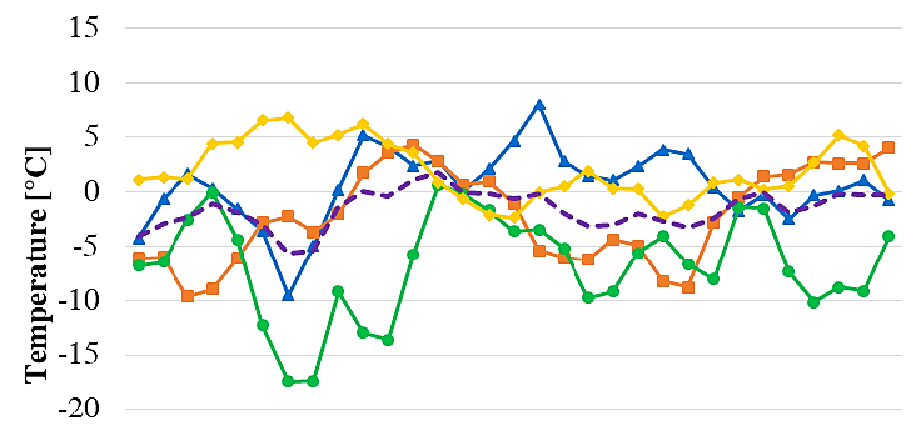

1. 3. 5. 7. 9. 11. 13. 15. 17. 19. 21. 23. 25. 27. 29. 31.

Day in January

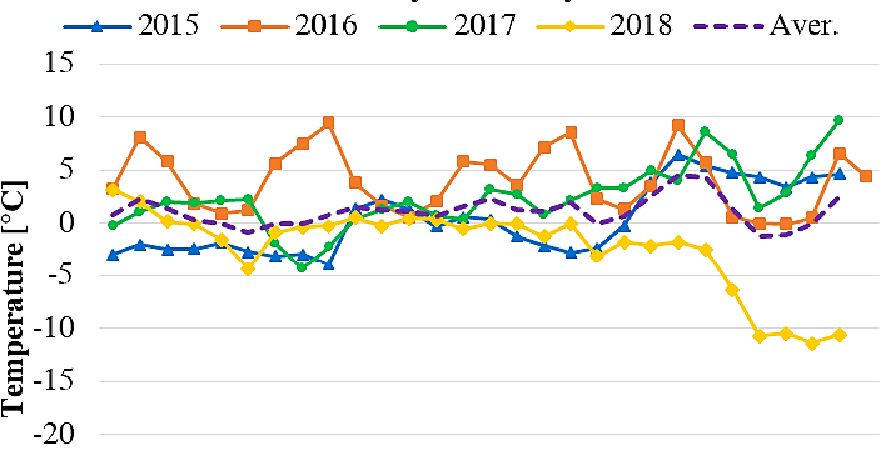

1. 3. 5. 7. 9. 11. 13. 15, 17, 19, 21, 23, 25, 27, 29. Day in February

$\longrightarrow 2015 \rightarrow 2016 \longrightarrow 2017 \rightarrow 2018---$ Aver.

Fig. 4: Detailed look at selected temperature extremes in a cold half-year (January - top, February bottom).

Temperature extremes (the cold ones) during year 2018 were at the end of February and beginning of March (Fig. 4 - bottom, Fig. 5 - top). 


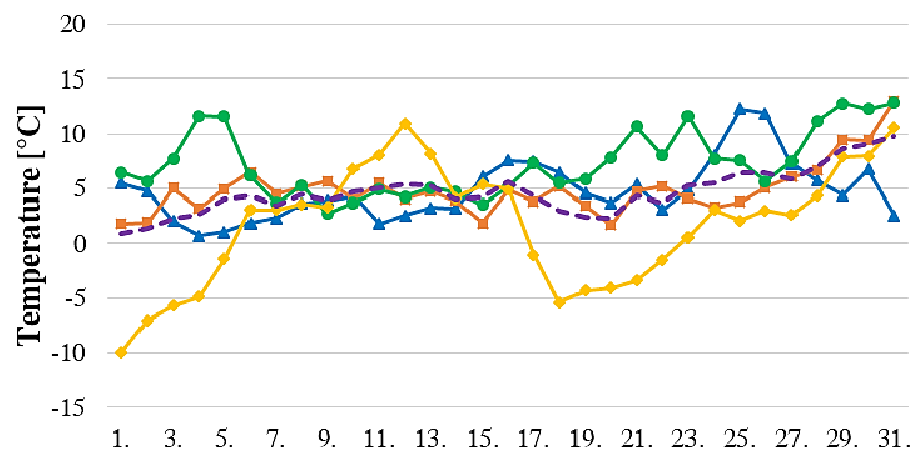

Day in March

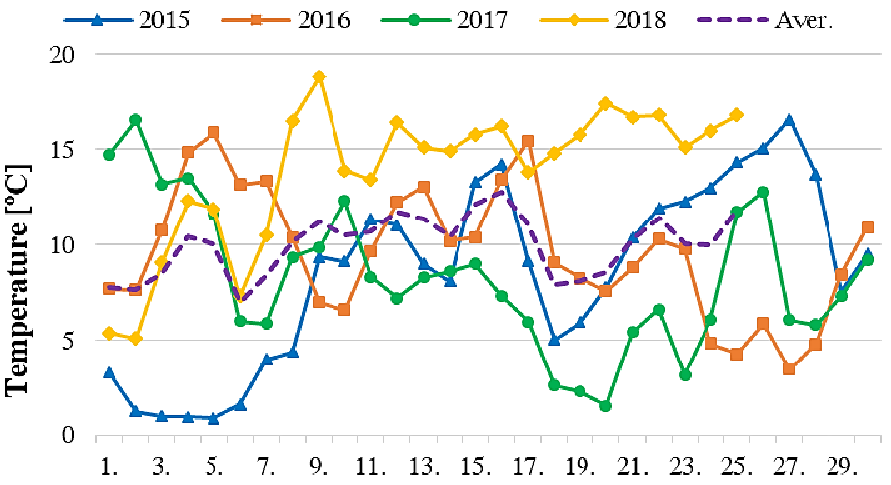

Day in April

$\longrightarrow 2015 \longrightarrow-2016 \multimap 2017 \multimap 2018 \quad=-=$ Aver

Fig. 5: Detailed look at selected temperature extremes in a cold half-year (March - top, April - bottom).

Maximum temperature from evaluated time period (2015 - 2018) in April was recorded in 2018 $\left(+18.8{ }^{\circ} \mathrm{C}\right)$, minimum temperature in $2015\left(+0.9^{\circ} \mathrm{C}\right)$. The maximum difference in yearly averages for April was $5.5 \stackrel{\circ}{ } \mathrm{C}$. The year 2018 was evaluated only until 25 April, because of the technical break calibration (Fig. 5 - bottom). A warm half-year is a period April - September, the cold half-year is October - March. Only in March 2018 there are recorded temperatures below zero.

Table 1: Monthly mean, minimum and maximum air temperatures for years 2015 - 2017.

\begin{tabular}{|c|c|c|c|c|c|c|c|c|c|c|c|c|c|}
\hline & Jan & Feb & Mar & Apr & May & Jun & Jul & Aug & Sep & Oct & Nov & Dec & Year \\
\hline \multicolumn{14}{|c|}{2015} \\
\hline$\theta_{m m}$ & 0.6 & 0.3 & 4.9 & 8.5 & 13.0 & 17.2 & 20.8 & 21.7 & 15.1 & 9.4 & 5.5 & 2.6 & 10.1 \\
\hline$\theta_{s d m}$ & 3.8 & 4.0 & 4.4 & 6.2 & 4.3 & 5.0 & 5.9 & 5.9 & 5.2 & 4.2 & 5.0 & 2.7 & 8.8 \\
\hline$\theta_{\min }$ & -14.5 & -8.1 & -3.7 & -3.1 & 2.7 & 6.1 & 5.8 & 8.1 & 3.7 & 0.6 & -7.3 & -9.5 & -14.5 \\
\hline$\theta_{\max }$ & 11.3 & 11.3 & 17.1 & 23.2 & 25.3 & 30.1 & 34.8 & 35.3 & 32.7 & 21.1 & 17.4 & 8.5 & 35.3 \\
\hline \multicolumn{14}{|c|}{2016} \\
\hline$\theta_{m m}$ & -2.2 & 3.4 & 4.9 & 9.6 & 14.1 & 18.4 & 18.3 & 17.6 & 15.7 & 7.9 & 4.6 & -1.4 & 9.1 \\
\hline$\theta_{s d m}$ & 4.6 & 3.6 & 3.9 & 5.4 & 5.4 & 5.14 & 5.0 & 4.9 & 5.8 & 3.8 & 4.8 & 3.3 & 8.6 \\
\hline$\theta_{\min }$ & -16.3 & -5.9 & -3.6 & -2.4 & 1.1 & 6.6 & 8.2 & 6.3 & 3.9 & -1.7 & -6.0 & -10.3 & -16.3 \\
\hline$\theta_{\max }$ & 6.6 & 12.7 & 21.0 & 26.5 & 26.8 & 33.4 & 31.8 & 29.3 & 29.6 & 23.2 & 16.4 & 6.9 & 33.4 \\
\hline \multicolumn{14}{|c|}{2017} \\
\hline$\theta_{m m}$ & -6.7 & 0.1 & - & - & 14.7 & 18.8 & 18.5 & 19.9 & 13.4 & 9.0 & 4.2 & 1.4 & 9.6 \\
\hline$\theta_{s d m}$ & 5.4 & 2.5 & - & - & 5.3 & 5.3 & 4.8 & 6.3 & 4.1 & 3.9 & 3.3 & 3.4 & 9.9 \\
\hline$\theta_{\text {min }}$ & -25.0 & -5.4 & - & - & -1.1 & 7.4 & 6.7 & 6.6 & 5.2 & 0.2 & -3.4 & -8.8 & -25.0 \\
\hline$\theta_{\max }$ & 4.0 & 6.3 & - & - & 29.7 & 30.8 & 32.8 & 34.7 & 28.2 & 21.6 & 14.4 & 13.6 & 34.7 \\
\hline
\end{tabular}


Table 1 presents monthly and annual mean temperatures, calculated from the continuous measuring period of the year 2017. Following parameters according to [1] were used for the table presentation: $\theta_{m m}$ - monthly means, $\theta_{s d m}$ - standard deviation of the daily means from the monthly mean, $\theta_{\min }$ - the minimum value of the hourly dry-bulb outdoor temperatures, $\theta_{\max }$ - the maximum value of the hourly dry-bulb outdoor temperatures. $\theta_{y m}$ - the annual mean temperature, calculated from the daily means. Individual values are expressed to the nearest $0.1{ }^{\circ} \mathrm{C}$. Measuring interval for above mentioned calculations was set to 10 minutes, as well as for the graphic view (Fig. 3 - Fig. 5). Of interest, the lowest monthly mean was recorded in Lomnicky Stit (February 1965) and the temperature was $-18.1^{\circ} \mathrm{C}$ [11]. Also $\theta_{p 1}-\theta_{p 99}$ as the values of the hourly dry-bulb temperature at the $1 \%, 5 \%, 10 \%, 90 \%, 95 \%$ and $99 \%$ percentiles could be a part of the evaluation table. March and April 2017 were not evaluated because of technical break and missing relevant measurement (Table 1). 12 means and standard deviations of temperature for individual months were calculated. By obtaining a wider database of measurement (e. g. minimum 10 years) it would be possible to evaluate some repeating periods or actions.

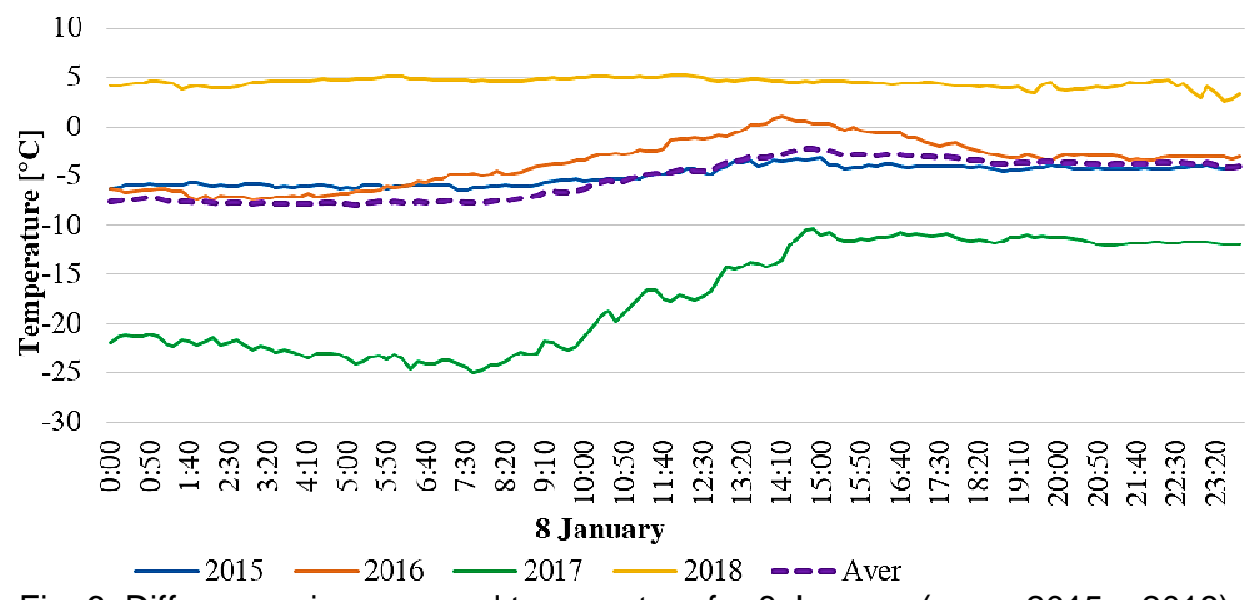

Fig. 6: Differences in measured temperature for 8 January (years 2015 - 2018).

For deeper analysis, 8 January 2017 was selected. Minimum temperature was recorded $-25.0{ }^{\circ} \mathrm{C}$, maximum temperature $-10.4{ }^{\circ} \mathrm{C}$, average was $-17.2{ }^{\circ} \mathrm{C}$. This day was characterized by Slovak Hydrometeorological Institute (SHMI) as a day with the lowest minimum temperature over the last 20 years. The low measured temperature is visible also from Fig. 3 and Fig. 4 - top, expressed by daily means.

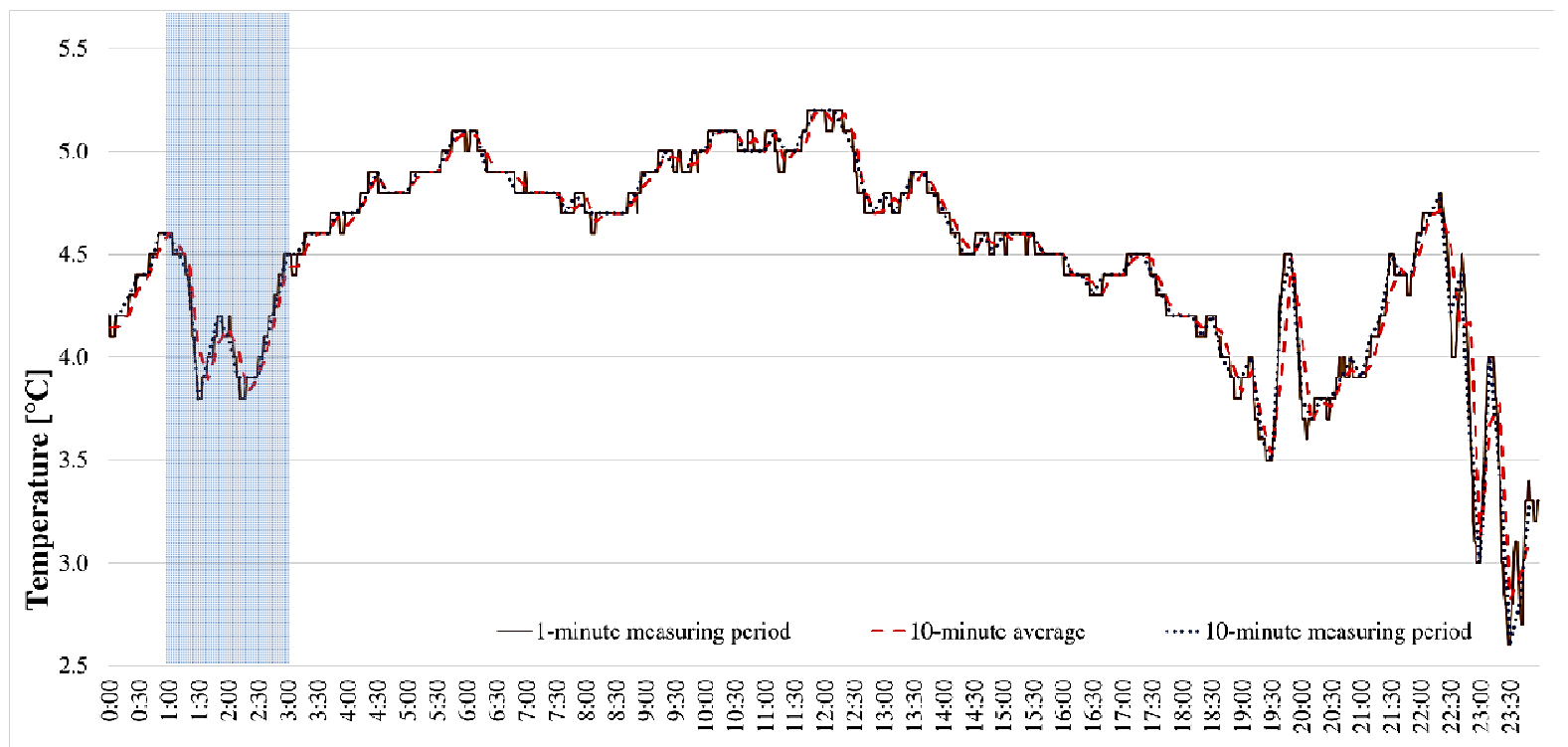

Time [min]

Fig. 7: Analysis of various temperature measuring intervals, 8 January 2017 (highlighted part is shown in Fig. 8 in detail). 
Temperature 10-minute average obtained from a real 1-minute measuring interval is represented in Fig. 7 by a smooth curve.

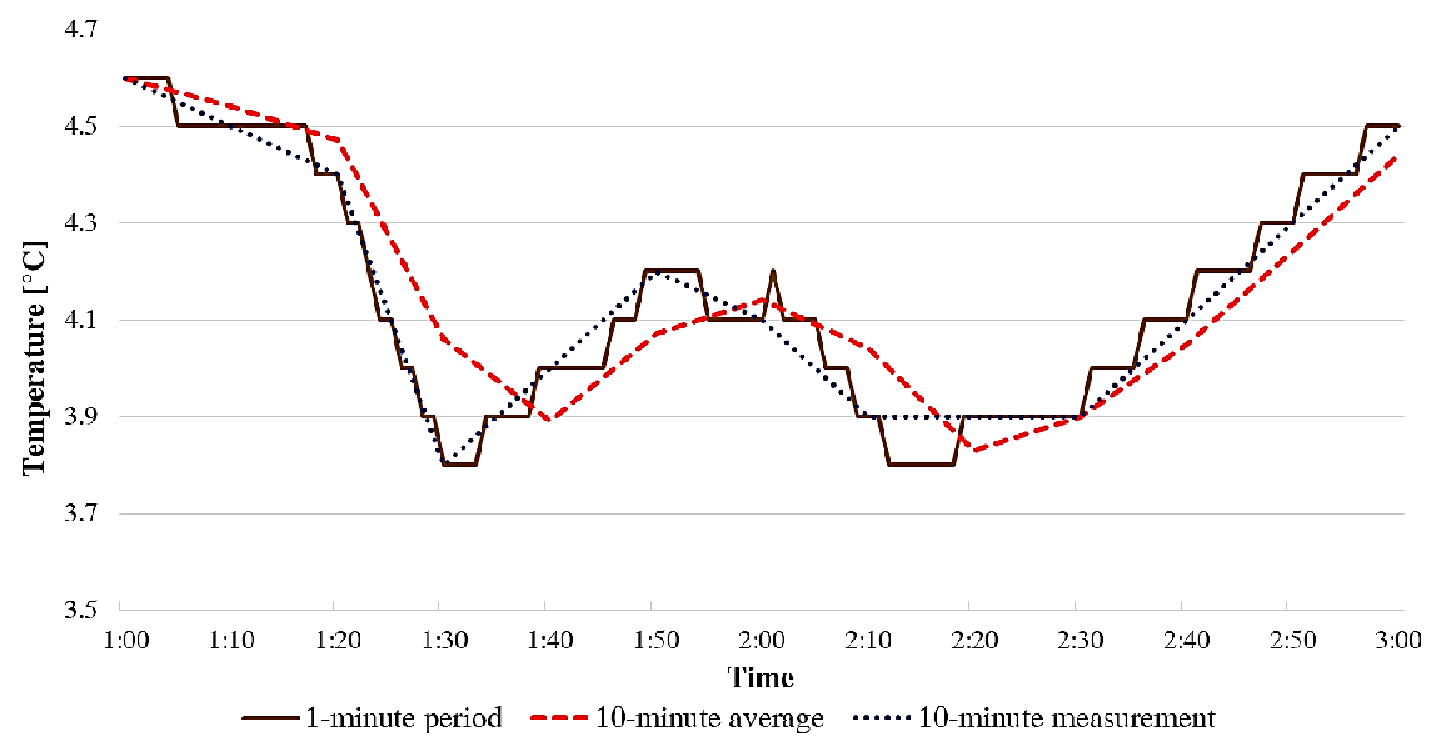

Fig. 8: Detailed look at differences in measuring/recording interval (area marked blue, Fig. 7).

As Fig. 8 shows in detail, there are visible differences by use of real measured values of temperature and averaged intervals. Usually it is complicated to state which approach is the most suitable. Temperature is a more stable variable in comparison, e. g. to wind direction, wind speed or solar radiation. Some databases include only daily means or mean temperatures available in 6-h or 12-h intervals [12]. Having own experimental weather station allows various comparisons of measuring intervals and it is free of charge (except purchase and service costs of course). Based on information from Fig. 8 it could be stated that a 10-minute measuring interval is more suitable than averaging values from the 1 -minute measuring period.

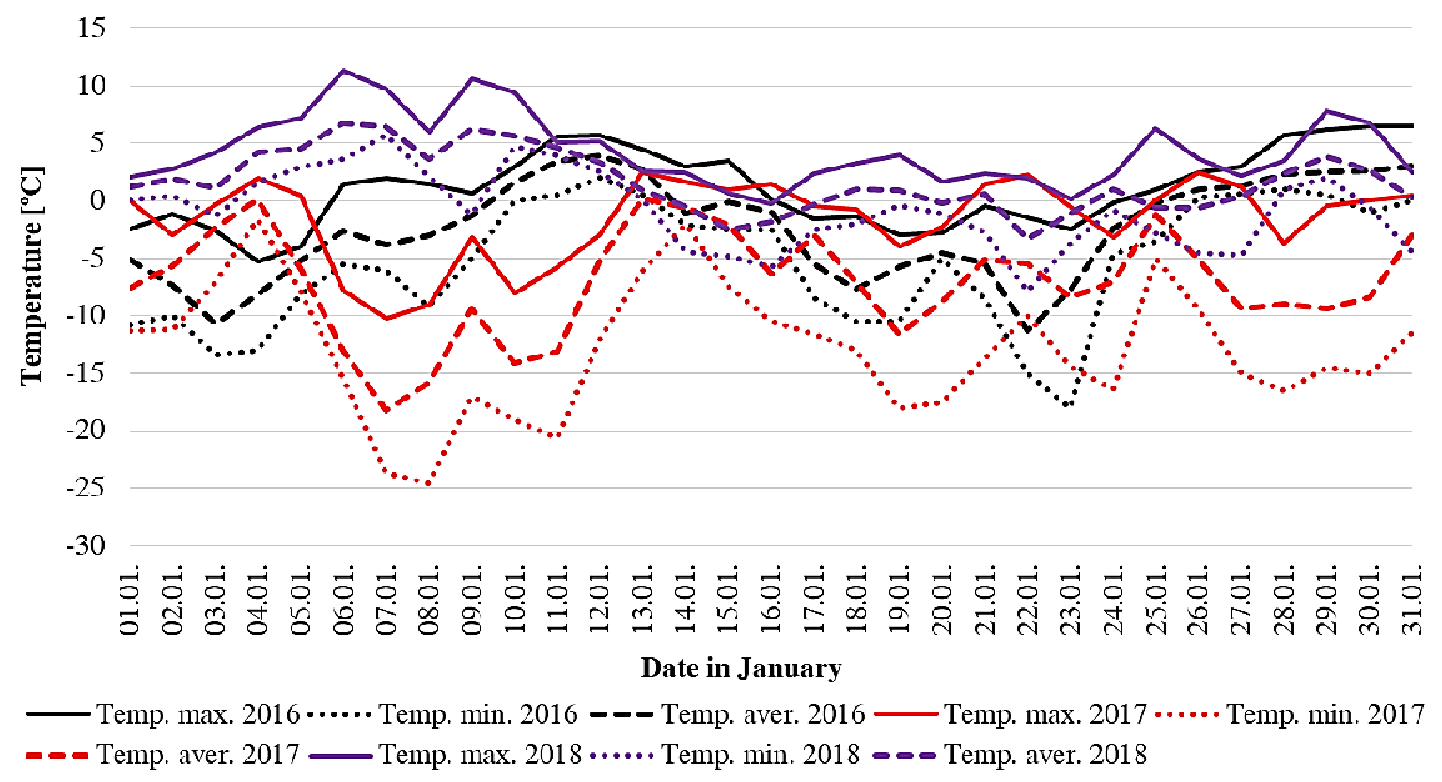

Fig. 9: Temperature measurement in Zilina, new weather station from SHMI network.

The year 2017 is interesting from the point of view of minimum temperature extremes (Fig. 9, 10) and the year 2018 of maximum temperature extremes (Fig. 9). As mentioned before, days 7 and 8 January 2017 were coldest in a period of last 20 years. Temperature differences among individual years in these selected days are nearly about $30^{\circ} \mathrm{C}$. In the middle of the month, the minimum temperatures differ at about $2 \stackrel{\circ}{ } \mathrm{C}$. The period 6 January -10 January $2016-2018$ shows the greatest variability of values. On the other hand 14 January shows the minimum difference among years 2016, 
2017 and 2018. The newly located weather station from the SHMI network is now in more similar surroundings than it was before the location change.

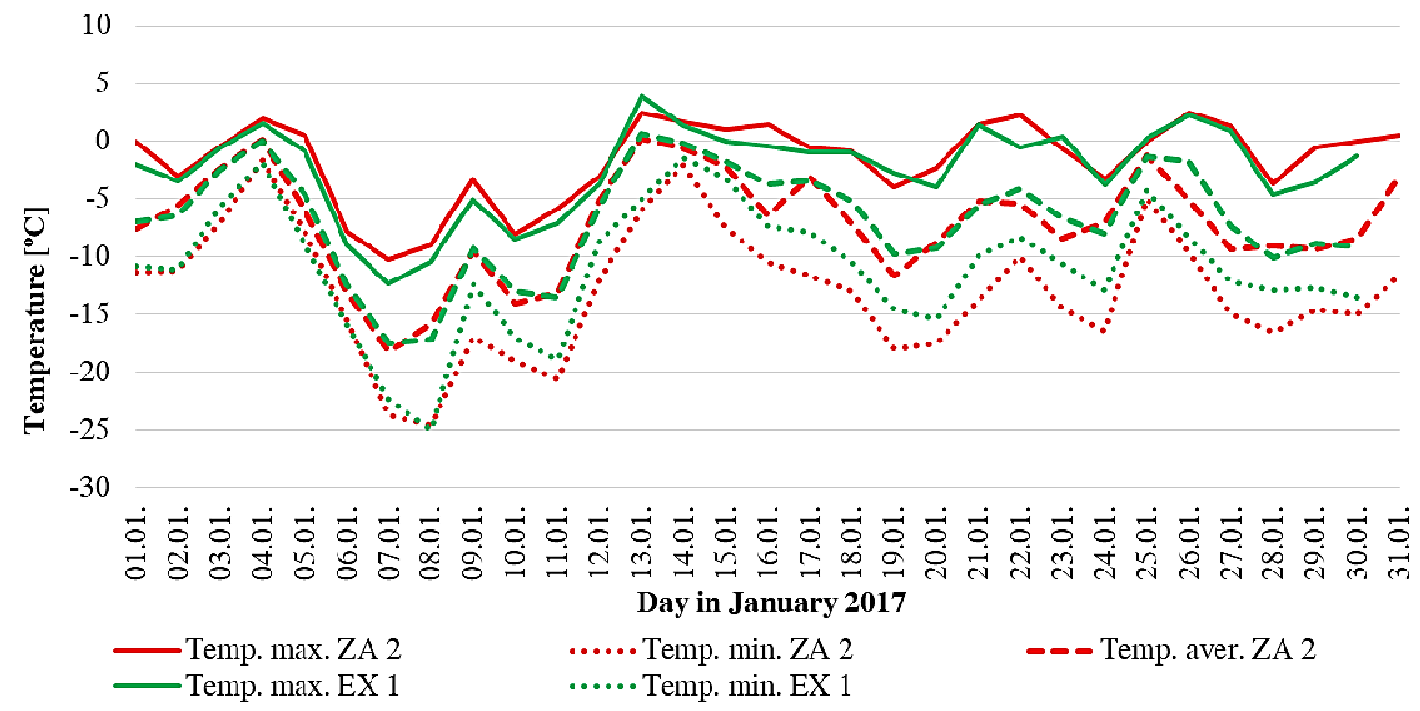

Fig. 10: January 2017 measured by various weather stations.

Temperature measurement is an integral but not the only one part for development of reference files for building simulations. These files are called Typical Meteorological Years (TMYs) used in the USA and Test Reference Years (TRYs) commonly marked in Europe [12]. Experimental weather station used for needs of this paper enables measurement of all necessary variables to generate the reference file in the future (after obtaining a file, which consists of minimum 5-year comprehensive measurement). Later on, the validation of a designed reference file follows, using it for some suitable simulation. Average Year of Temperature is crucial for today often-used building simulations [13]. EX 1 represents the first experimental weather station and ZA 2 is the sign of SHMI weather station located in the same town (Zilina), but a few kilometers far from the experimental laboratory.

Table 2: Example of mean temperatures for individual months of the year [8].

\begin{tabular}{|c|c|c|c|c|c|c|c|c|c|c|c|c|c|}
\hline \multicolumn{10}{|c|}{ Mean temperature for Bratislava, Slovakia } \\
\hline & Jan & Feb & Mar & Apr & May & Jun & Jul & Aug & Sep & Oct & Nov & Dec & Year \\
\hline$\theta_{e}$ & -2.0 & 0.0 & 4.3 & 9.6 & 14.2 & 17.8 & 19.3 & 18.9 & 15.3 & 10.0 & 4.2 & 0.1 & 9.3 \\
\hline
\end{tabular}

Table 2 presents a reference file, consisting of mean temperatures for individual months and also the annual mean for Bratislava. Comparing it to Table 1, even if it is also a town in Slovakia, the values differ from each other. In building simulation there are often used places with similar climate, but the most suitable is the measurement in exact locality.

\section{Results}

Analyzing a long-term temperature measurement during years $2015-2018$ it is clearly visible that the climate conditions (especially the temperature) are various and changing. To analyze and evaluate the measurement, a reference file was created to characterize the exterior conditions as precise as possible. This reference file is based on arithmetic mean, which characterizes the evaluated period best. From statistical point of view, the arithmetic mean (average) offers a set of results which reports central tendencies. It is to discuss if average or extremes are most suitable for building simulations. In the laboratory center of the Department of Building Engineering and Urban Planning (University of Zilina) the indoor climate can be set according to actual needs (laboratorycontrolled inner boundary conditions), whereas the outdoor climate conditions are real, measured by the experimental weather station. Selected results from measurement are presented in this paper. Continuous measurement with variable recording interval offers the possibility of evaluation in detail. Having own weather station, which enables measurement meteorological and radiation data sets has 
a great potential. Composing a TRY prefers sequences of real measured data for creation of the most suitable file to be used by a building simulation. Generated individual temperature values often differ from the measured ones considerably. Averaging softens the difference in values.

\section{Acknowledgements}

This article was created with support of the grant project VEGA No. 1/0683/16 and also with provided data and consultation from Slovak Hydrometeorological Institute in Bratislava (SHMI).

\section{References}

[1] STN EN ISO 15927 - 1. Hygrothermal performance of buildings - Calculation and presentation of climatic data - Part 1: Monthly means of meteorological elements, 2003.

[2] CUI, Y. et al.: Comparison of typical year and multiyear building simulations using a 55-year actual weather data set from China. Applied Energy Vol. 195, 2017, pp. 890 - 904.

[3] STAFFENOVA, D. et al.: Climate Data Processing for Needs of Energy Analysis. Advanced Materials Research Vol. 1041, 2014, pp. 129 - 134.

[4] SOUBHI. A. H. - OSAMA, K. O. - WALEED. A. A. F.: An Experimental Investigation of Temperature Distribution in Different Urban Locations in Aswan, Egypt of Hot and Dry Climate. Computational Water, Energy and Environmental Engineering, Vol. 2, No. 2, 2013, pp. 69 - 75.

[5] Research task of a grant No. 09: External climate model - Reference year for the 1st temperature area of Slovakia. Bratislava, 1993 (in Slovak).

[6] RIOS, F. C. et al:: Analyzing the Impact of Outside Temperature on Energy Consumption and Production Patterns in High-Performance Research Buildings in Arizona. Journal of Architectural Engineering, Vol. 23, Iss. 3, 2017.

[7] https://ascelibrary.org/doi/10.1061/\%28ASCE\%29AE.1943-5568.0000242.

[8] Building performance simulation for design and operation. Spon Press, 2011.

[9] SANDERS, C.: IEA Annex 24. Final report. Volume 2. Task 2: Environmental conditions. Heat, Air and Moisture Transfer in Insulated Envelope Parts (Hamtie), Acco Leuven, 1996.

[10] KOCI, J. - MADERA, J. - CERNY, R.: Determination of the Positive Weather Year for Application in Hygrothermal Simulations. WIT Transactions on Modelling and Simulation, Vol. 59, 2015, pp. $97-107$.

[11] DALL'AMICO, M. - HORNSTEINER, M.: A simple method for estimating daily and monthly mean temperatures from daily minima and maxima. International Journal of Climatology, Vol. 26, Iss. 13, 2006, pp. 1929 - 1936.

[12] Record values of meteorological variables around the world and in Slovakia. Cited online: $<$ http://www.nun.sk/rekordy.htm>.

[13] YLHAISI, J. S. - RAISANEN, J.: Twenty-first century changes in daily temperature variability in CMIP3 climate models. International Journal of Climatology, Vol. 34, Iss. 5, 2014, pp. 1414 1428.

[14] BILBAO, J. - MIGUEL, A. - FRANCO, J. A.: Generation of a Test Reference Year of global solar radiation from a Test Reference Year of Temperature, January, 2000. 